\title{
Os inventos e a pintura de Leonardo da Vinci
}

\author{
Mario Taddei
}

Fundador do Museu Leonardo3, entrevistado por Leila Kiyomura, do Jornal da USP em 09/04/2019.

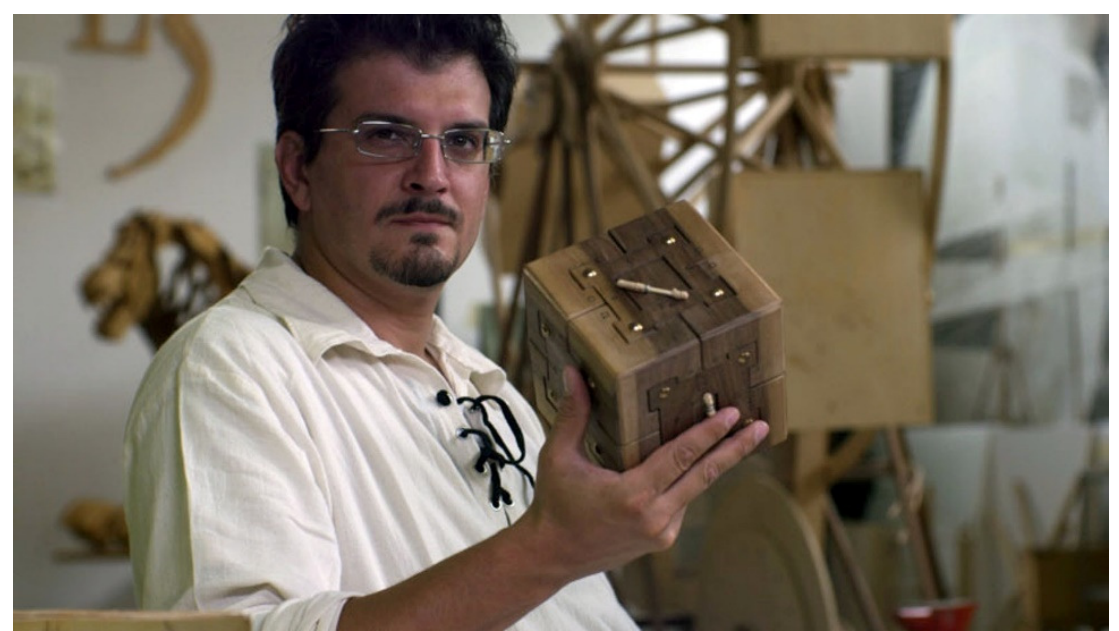

Desvendar cada linha das incontáveis páginas escritas por Leonardo da Vinci é o caminho que o pesquisador Mario Taddei vem trilhando há 15 anos para buscar o verdadeiro gênio da arte e da ciência. Uma busca que resultou em diversos livros, exposições e a fundação do Museu Leonardo 3, em Milão. Foi a história da pesquisa e da descoberta desses manuscritos que abriu o $2^{\circ}$ Congresso de História da Ciência e da Técnica: Desafios Contemporâneos realizado de 8 a 10 de abril de 2019, no Anfiteatro Nicolau Sevcenko, no prédio de Geografia e História da Faculdade de Filosofia, Letras e Ciências Humanas (FFLCH) da USP. O evento foi organizado pelo Centro de História da Ciência (CHC) da USP, contando com a colaboração do Instituto de Estudos Avançados (IEA), também da USP.

Mario Taddei vem construindo, na forma original, os inventos do cientista como a asa voadora ou ornitóptero, as máquinas militares, os equipamentos de mergulho, submarinos, entre outros 200 projetos de Leonardo da Vinci. 
Em entrevista exclusiva para Leila Kiyomura, do Jornal da USP, o pesquisador observa que a produção do célebre pintor é muito pequena diante dos inventos do cientista. Porém, reconhece: “Apenas o tratado de pintura publicado após a sua morte contribuiu grandemente para a história da arte. Mas se ele tivesse publicado seus estudos mecânicos e científicos, hoje já estaríamos em Marte".

No decorrer deste ano, os 500 anos da morte de Leonardo da Vinci serão reverenciados. Para Mario Taddei, o mais importante é continuar apresentando o trabalho do pintor cientista como uma referência para as novas gerações. "Uma arte e ciência para que as nossas crianças e jovens possam entender que, com estudo e paixão, todos podem se tornar Leonardo da Vinci.”

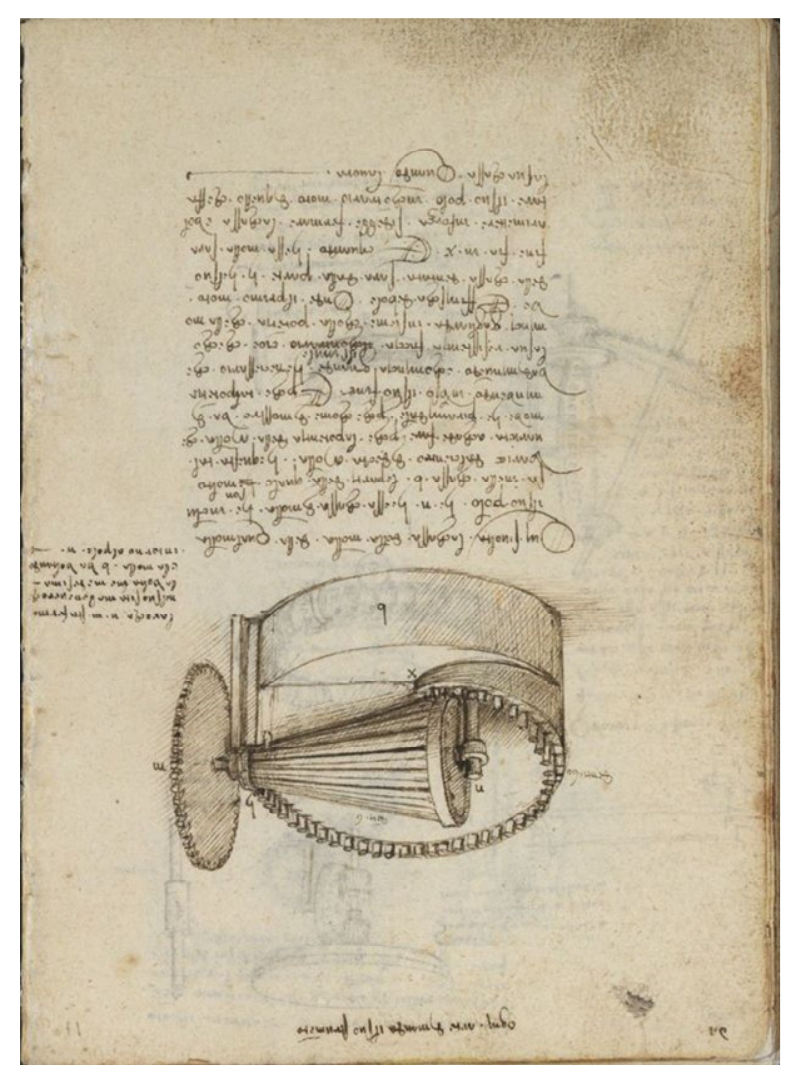

Como o senhor analisa a criatividade de Leonardo da Vinci como artista e cientista?

Mario Taddei - Leonardo é universalmente conhecido como o maior artista de todos os tempos, mas quantas pinturas ele realizou em sua vida? Se pensarmos sobre isso, fez muito pouco. No entanto, ganhou notoriedade como o maior gênio de todos os tempos. E ele é realmente um grande gênio, o inventor de incríveis máquinas e precursor de tudo o que temos hoje: avião, carro, tanque, paraquedas, metralhadora, helicóptero e é 
apontado até mesmo como o inventor da bicicleta. Isto é divulgado em inúmeras exposições e livros que estão espalhados por todo o mundo. Mas infelizmente tudo isso é falso. Inicialmente, eu também acreditei em todas essas coisas. Mas quando comecei a estudar e pesquisar os manuscritos de Leonardo, fui me deparando com a verdade, que pode ser terrível, porém, fascinante e importante. Leonardo copiou as máquinas famosas que foram atribuídas à sua autoria. Para dar dois exemplos muito simples, basta pensar no desenho do homem inscrito em um círculo e um quadrado, o conhecido " $\mathrm{O}$ Homem de Vitrúvio". Esta ilustração foi criada a partir do conceito do arquiteto Marcos Vitrúvio Polião. Leonardo copiou e documentou o seu conceito. Porém, agora ninguém lê mais os documentos. Todos confiam no sentimento comum e no que é dito em livros estúpidos, documentários e exposições horríveis.

Os manuscritos então derrubam o mito do gênio revolucionário? Há outros exemplos que o senhor destacaria?

Mario Taddei - Outro exemplo é a máquina que usei quando criança em um museu. Ou seja, um parafuso inclinado que girava em uma bacia de água. Muitos atribuem a invenção a Leonardo, mas na realidade é o parafuso de Arquimedes, que viveu entre 287 e 212 a.C. Leonardo estudou o parafuso e desenhou uma nova versão. A bicicleta é, em seguida, um escárnio colossal, foi desenhada em 1800 por alguém dentro do código do Atlântico e muitos acreditavam que era do pintor inventor.

\section{Então qual é a verdadeira face do inventor?}

Mario Taddei - A coisa incrível que me levou a "revolucionar" os estudos sobre Leonardo é que, uma vez superados esses famosos e falsos assuntos, ainda existem cerca de 6.000 manuscritos reveladores. Depois de copiar as primeiras 20/30 máquinas famosas de autores e livros medievais e renascentistas, Leonardo apaixonou-se por ciência e mecânica e começou a inventar e desenvolver novas máquinas e novos conceitos. No entanto, estes são difíceis de interpretar porque Leonardo não criou belos desenhos que são compreensíveis para todos. Meu trabalho por mais de 15 anos tem sido buscar e pesquisar este novo Leonardo, muito mais fascinante e importante do que todos acreditam saber. O segredo de Leonardo, o verdadeiro é, portanto, o de ter estudado e copiado muito. Um trabalho que o levou à paixão e dedicação às novas descobertas. Em Milão, em 1482, ele torna-se o grande artista e cientista, utilizando a natureza como a grande ferramenta da criatividade.

Quando e por que o senhor decidiu construir as invenções de Leonardo da Vinci? 
Mario Taddei - Comecei a construir as máquinas simples e triviais de Leonardo quando jovem, copiando aquelas feitas em museus, quando, mais tarde, percebi que o verdadeiro Leonardo esconde suas máquinas reais em manuscritos difíceis de interpretar. Porém, continuei montando suas máquinas com o firme propósito de entender se esses trabalhos e, acima de tudo, a construção direta de suas máquinas são os caminhos para entender seriamente as anotações que ele nos deixou. O próprio Leonardo escreveu e nos ensinou que não há conhecimento sem experiência. Portanto, é através da experimentação prática da construção das máquinas que busco encontrar o verdadeiro espírito de Leonardo. A prática e a experimentação direta na pintura e na construção de máquinas são os instrumentos de investigação para chegar aos manuscritos do cientista. De outro modo, a verdadeira história de Leonardo ficaria à mercê apenas de livros e textos filosóficos que ele tanto odiava e evitava.

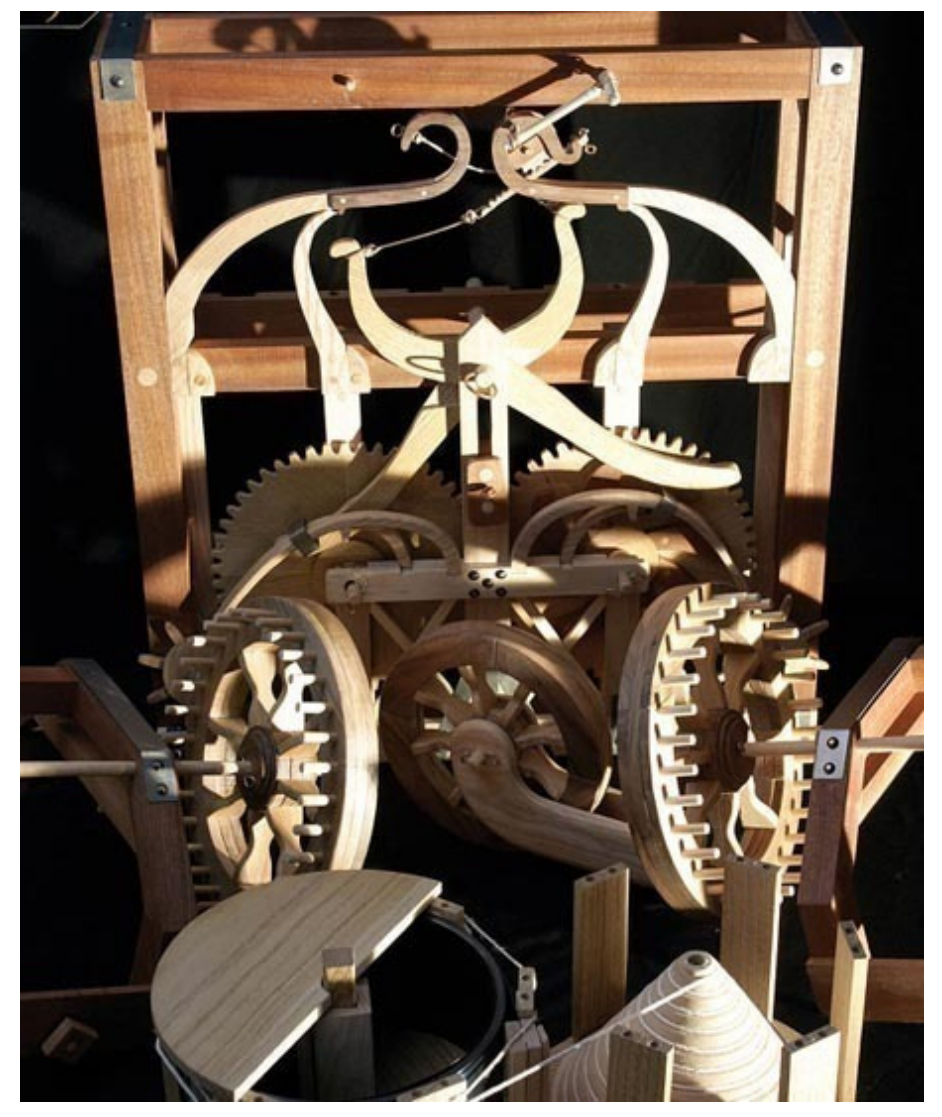

\section{Como o senhor analisa o impacto dessas invençôes?}

Mario Taddei - Se Leonardo realmente tivesse inventado um helicóptero, um avião e um carro, hoje o mundo inteiro deveria muito dinheiro com direitos autorais para Leonardo! Na realidade, infelizmente, todos os seus estudos permaneceram escondidos em seus cadernos e em seus códigos e não contribuíram muito para a história da ciência 
porque nunca foram publicados. Apenas o tratado de pintura publicado após a sua morte contribuiu grandemente para a história da arte. Mas se ele tivesse publicado seus estudos mecânicos e científicos, hoje já estaríamos em Marte. No entanto, algumas máquinas e experiências de Leonardo deram o estímulo e o conhecimento para criar outras máquinas. A história lembra, por exemplo, seu leão robô, que inspirou outros robôs ano após ano. É assim que a história funciona.

Quais são as contribuições da trajetória de Leonardo da Vinci para o conhecimento atual?

Mario Taddei - Como expliquei, Leonardo não pôde publicar seus estudos e muito se perdeu. Suas pinturas e o tratado de pintura são a base da arte dos séculos seguintes. Mais do que um inventor de máquinas, Leonardo é um homem que inspirou e impressionou gerações inteiras. Hoje, sua importância é fundamental para incentivar os jovens a estudar e usar a criatividade como ele fez. "Uma arte e ciência para que as nossas crianças e jovens possam entender que, com estudo e paixão, todos podem se tornar Leonardo da Vinci..."

\section{Como o senhor conseguiu reconstruir essas invenções?}

Mario Taddei - Minha pesquisa é baseada principalmente no uso de tecnologia digital. Depois de estudar livros, tratados e observar os originais, o trabalho vai para o computador, onde posso fazer os modelos e experimentos de Leonardo em um ambiente virtual. Criei uma espécie de carpintaria virtual infinita, um laboratório virtual onde é possível construir máquinas e ver se elas funcionam antes mesmo de ir ao laboratório. Uma vez que os modelos em animação e funcionamento 3D são realizados, é mais fácil fazer o modelo de madeira real no laboratório. A realização prática do modelo é fundamental, mas, muitas vezes, percebemos como algumas coisas realmente funcionam e outras não. O feedback contínuo entre realidade e virtual permite que você ajuste e experimente até chegar a um protótipo em um curto espaço de tempo.

\section{Há quanto tempo você está pesquisando e quem está patrocinando este traba- Iho?}

Mario Taddei - Na verdade, pesquiso Leonardo da Vinci desde criança, e aos poucos, livro a livro, fiz centenas de máquinas e milhares de modelos tridimensionais. Inicialmente escrevi livros para outras editoras e organizei exposições com outros autores importantes. Carlo Pedretti, por exemplo, me ensinou a ler Leonardo diretamente. Então, depois de ter fundado a empresa Leonardo3 com Edoardo Zanon e Massimiliano Lisa, conseguimos realizar primeiro uma exposição e depois um museu no centro de 
Milão, na Piazza Scala. Trata-se do Museu Leonardo3, onde é possível observar um Leonardo nunca visto antes, incluindo todos os estudos, fatos e milhares de manuscritos. E hoje, além do museu, temos algumas exposições itinerantes que viajam pelo mundo para trazer essa nova visão para todos. Nunca recebi nenhum financiamento e foi muito difícil no começo, mas sem jamais desistir. Hoje, tudo o que fazemos é financiado pelas mesmas exposições e pelo nosso museu com apenas a participação dos visitantes. O mais importante para mim é inspirar as novas gerações. Revelar os inventos e o pensamento que Leonardo deixou. Uma arte e ciência para que as nossas crianças e jovens possam entender que, com estudo e paixão, todos podem se tornar Leonardo da Vinci. 